See discussions, stats, and author profiles for this publication at: https://www.researchgate.net/publication/332116038

\title{
Contesting shopping tourism: Neoliberal consumptionscapes and conflicts in host societies
}

Article in Tourism Culture \& Communication · June 2019

DOI: $10.3727 / 109830419 \times 15536971539434$

CITATION

1

2 authors, including:

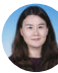

Wei-Fen Chen

University of Leicester

9 PUBLICATIONS 4 CITATIONS

SEE PROFILE

Some of the authors of this publication are also working on these related projects:

Project Digital Media Activism for Democracy Movement in Hong Kong View project

Project $\quad$ Orchestrating Furry Cuties Online: The Social Media Performance of Cream Bro - the most influential cat in Hong Kong View project
READS

25 


\title{
CRITICAL REVIEW
}

\section{CONTESTING SHOPPING TOURISM: NEOLIBERAL CONSUMPTIONSCAPES AND CONFLICTS IN HOST SOCIETIES}

\author{
WEI-FEN CHEN* AND TIN-YUET TING $\dagger$ \\ *Institute for Advanced Study, Institute for Emerging Market Studies, \\ The Hong Kong University of Science and Technology, Kowloon, Hong Kong \\ $\nmid$ Department of Applied Social Sciences, The Hong Kong Polytechnic University, Kowloon, Hong Kong
}

\begin{abstract}
In this "cutting edge" review article, Chen and Ting maintain that new middle class tourists (especially those consumption-driven, urban dwellers from emerging economies) have acquired a taste for shopping tourism and quickly become the majority of the inbound visitors who bring business niches to the postindustrial host societies. They argue that under this trend, scant scholarly attention has been paid to the corresponding reactions, confusions, and concerns in the host societies. This article thereby offers a critical reflection on the manifestation of "unwelcome shopping tourism" as well as its local resistance and conflict in the context of changing consumption milieu contributed by the growth of Chinese tourists worldwide. The authors discuss and challenge the neoliberal presupposition guiding much of today's shopping tourism agenda that tends to maximize short-term business interests at the expense of local consumers' mundane lifestyles and native cultural identities. Chen and Ting thus propose a typology of conflicts pertaining to the growing tensions between local residents and shopping tourists, which should inform issues regarding local residents' political consumptions and sustainable tourism development in global cities. (Abstract by the Reviews Editor)
\end{abstract}

Key words: Shopping tourism; Consumption; China; Conflict; Neoliberalism; Host society

Introduction: Unwelcome Tourist Shoppers from China

A significant increase in Chinese outbound tourists has been recorded in many countries around the globe. What makes the case of Chinese tourists particularly interesting is that they, compared to tourists from other countries, tend to prioritize shopping as their prime motivation of traveling, and spend a larger proportion of their total expenditure on shopping (Brasor \& Tsubuku, 2015; Ryall, 2015). For instance, a Chinese tourist on average

Address correspondence to Tin-Yuet Ting, Research Assistant Professor, Department of Applied Social Sciences, The Hong Kong Polytechnic University, GH312, Hung Hom, Kowloon, Hong Kong. E-mail: tyting@polyu.edu.hk 
spends 1,100 euros per trip in Paris, more than tourists from any other country (Mangin, 2015). In Japan, Chinese tourists accounted for $27.5 \%$ of all tourists' expenditure in 2014, and the number rose to over 30\% in 2015 (Brasor \& Tsubuku, 2015; Ryall, 2015). A similar trend has been observed in Hong Kong, where mainland Chinese tourists contributed to one third of total retail sales (Liu, 2014). This being the case, Chinese outbound tourists have given rise to a new spree of shopping tourism worldwide. This article aims to acquaint readers with the phenomenon of Chinese tourist shoppers by shifting the analytic focus from the mainstream lens of lucrative business niches to the often overlooked social costs (that is, the corresponding reactions, confusions, and concerns in the host societies).

Chinese tourist shoppers have become a common scene shared by major global cities. With approximately 7 million usual residents, Hong Kong as a special administration region of China hosted over 50 million visitors in 2016, including more than 42 million tourists from mainland China. Paris, one of Chinese tourists' new favorite destinations, received 600,000 to 800,000 Chinese tourists in 2014, an increase of nearly $20 \%$ from the previous year (Mangin, 2015). Chinese shoppers also made a high-profile presence in many other European countries such as the UK, Germany, Belgium, Italy, and the Netherlands. In response, global brands and tourist service businesses target these tourist shoppers by providing diverse luxurious products along with other commodities and shopping tourism packages (Park, Reisinger, \& Noh, 2010).

Although shopping tourism that capitalizes on urban space and local livelihood has engendered a wide range of repercussions and has recently encountered resistance from local communities, relatively few studies have examined how the seemingly promising economic gain is actually lived by local residents, whose everyday practices, stances, and attitudes may not have been fully addressed in conventional top-down approaches that tended to overlook the uneven distribution of positive and negative externalities among individuals in the host society (Sonnenburg \& Wee, 2016).

In this article, we offer a critical reflection on the manifestation of "unwelcome shopping tourism" as well as its local resistance and conflicts in the context of changing consumption-scape contributed by the proliferation of Chinese tourists. In the following sections, we first discuss and challenge the neoliberal presupposition guiding much of today's shopping tourism agenda. Subsequently, we propose a typology of conflicts pertaining to the growing tension between local residents and the tourist shoppers.

\section{Neoliberalism and Shopping Tourism}

From a critical perspective of political economy, tourism plays an important role in expanding and maintaining capitalism by introducing noncapitalist space to the global capitalist system (Mosedale, 2016). Shopping tourism attracts inbound tourist shoppers through a set of neoliberal policies and corresponding activities that integrate local communities into the global marketplace. On the one hand, shopping tourism creates and reconstructs consumerfriendly urban space that facilitates tourist consumption. On the other hand, it establishes and redefines normative ideas about how to best serve the host society, and which roles of local communities and residents should be prioritized in the new or renewed consumption-scape. Shopping tourism as a neoliberal process thus reproduces through both concrete practices and intangible discourses.

Urban reconstruction and dispossession are often enforced under the neoliberal initiative of tourism development. In these processes, the state undertakes a "spatial fix" by transforming existing sociospatial relations and meanings into abstract space that is privatized for consumer commodities (Harvey, 2005). More often than not, it separates local residents from the urban space and their livelihood in the city by assigning priorities to the new consumption-driven economy. In the case of shopping tourism, local governments have facilitated the construction of luxury malls and transportation systems to connect key shopping destinations (Josiam, Kinley, \& Kim, 2005; Park et al., 2010). Nowadays, major global cities such as Dubai and Las Vagas compete to offer a broad range of luxury retailing services for tourist shoppers (Anwar \& Sohail, 2004; Holly, 2002). At the same time, however, competition for prime locations warranted by neoliberal policies may lead to a land price explosion in those areas, where local residents' access to land, resources, and decent living conditions has been constrained. 
In developing shopping tourism, a common practice has been branding and building a local community as a global marketplace. In the past, global mega-events such as the World Cup were turned into tourist attractions to generate business niches for private entrepreneurships through the deregulation and reregulation of state policy at multiple levels (Hall, 2006). Nowadays, governments have competed to organize shopping festivals to boost domestic retailing trades in major global cities, such as London, Tokyo, Hong Kong, and Dubai. By offering discounts to tourists and by regularly putting on special events, the urban landscape seems to become a synonym of consumption experiences, especially when cities are dubbed "Shopper's Paradise" (GovHK, 2015).

However, structural disadvantages are largely ignored in neoliberal discourses. For one, there may be little trickling down of the economic gains from tourist shoppers. Rainer (2011) discussed the neoliberal project of developing the Salta Wine Region in Argentina into a premium tourism attraction through producing new spaces for leisure consumption. This project, he concludes, merely "benefits the land holding elites and new investors while escalating cost of living and unequal access to resources" (p. 104). A potential of conflict may thus occur in shopping tourism, as different social entities struggle over how societal resources and urban landscape should be interpreted and managed. For example, the "tourism phobia" in some European cities is fueled by the anticapitalist ideology. It has been suspected that the way for tourists to save the postcrisis economy is to sacrifice the social and environmental well-beings of local citizens (Coldwell, 2017).

Given the contested nature of neoliberal processes, it is crucial to study not only the tourist shoppers and their consumption patterns, but also their interactions with local residents in the everyday domain. Examining the impact of tourism on local community interests, Knopp (1981) proposed using "nonrecreation" (removable or transportable goods), "recreation" (the use of surrounding environments), and "lifestyle" (unique local symbols and behavior patterns) to describe local residents' relationships to land resources, which can be affected by inbound tourists. Concurrently, Rainer (2011) focused on the issues of access to resources, affordable living, and livelihood improvement in studying how conflicts may emerge in premier and leisure tourism. In the next section, we extend Knopp's (1981) and Rainer's (2011) insights into contesting resources and interests to discuss how they, when distributed unevenly, may lead to corresponding forms of conflict. The three forms of conflict capture the impact of current shopping tourism on host societies, highlighting issues and variations worldwide.

\section{A Typology of Conflicts in the} Changing Consumption-Scape

\section{Conflict Over Commodities}

The first conflict type revolves around excessive shopping for commodities by tourists that are also demanded by local consumers, thereby causing shortage in product supply. Especially after the food scandal of the "poisonous baby formula," which is believed to cause the death of six newborns and to sicken nearly 300,000 in 2008 (Jacobs, 2008), some mainland Chinese consumers seeking higher quality goods have excessively bought baby formula across the world, leaving insufficient quantities to local newborns (Pei et al., 2011). This trend has been observed in many popular travel destinations such as Germany, Australia, the UK, and Hong Kong (Grieshaber, 2013; Korporaal, 2017). Due to the shortage, the Hong Kong authority had to introduce a ban in 2013 to limit the quantity of baby formula that travelers are allowed to carry when departing Hong Kong.

Besides buying out baby formula, excessive shopping practices of Chinese tourists have been noted in other commodities. In Japan, one of the recent buzzwords in the media has been bakugai (Demetriou, 2016; Ryall, 2015). Bakugai refers to the explosive shopping spree carried out by Chinese tourists who like to purchase the "four treasures" in bulk, namely rice cookers, toilet seats, thermos mugs, and ceramic knives, among other madein-Japan products (Hong, 2015; Mollman, 2015). Moreover, while products distributed overseas are perceived to be more reliable than their mainland Chinese counterparts, the geographical proximity between Hong Kong and China has allowed a rise of cross-border trading businesses. These crossborder traders have purchased a great deal of goods in Hong Kong, such as food, wine, cosmetics, skincare products, daily necessities, shoes, mobile phones, 
and other electronic products, and then resold them in China for profits (Lee, 2014; Liu, 2014).

As local residents' shopping outlets become the source of goods for tourist shoppers and cross-border traders, the locals have to compete with foreign buyers to secure enough resources for personal use. Such conflicts of interest have resulted in tension and have stirred responses from local residents and shopkeepers. In New York, where Chinese tourists strategically and extravagantly shop for luxuries that are unavailable or overpriced in China, counterpractices against such excessive shopping have emerged. Recently, a manager of the Macy's flagship department store in Manhattan was alleged to instruct the staff to racially profile Chinese customers and to limit the quantity of their purchase (Horwitz, 2017).

\section{The Segregated Marketplace}

In the next type of conflict, local residents are mainly affected by the changing marketplace, which is transformed to address the needs of tourist shoppers. In the past, urban planning accommodating tourism was found to undermine local lifestyles through redevelopment projects that revitalize and commodify neighborhoods into standardized tourist enclaves (Lloyd, 2002). In contrast, recently the impact of tourist shoppers from China has segregated the consumption-scape of the original urban centers in major global cities.

Targeting tourist shoppers from China, global brands have established major stores and malls in prime districts, selling luxuries such as leather goods, jewelry, electronics, and cosmetics. As the rents of business areas are bolstered by global brands that open flagship stores, small local shops that target local consumers, such as local diners, clinics, and grocery stores, have been either squeezed out to nonpremium locations or closed due to decreasing profits (Wassener \& Hui, 2014). Furthermore, shopping tourism often proliferates to other dimensions in host societies, as tourist-oriented businesses capitalize on surrounding local communities by linking them with supportive activities. For instance, in Paris, one of the most desired destinations among Chinese tourist shoppers, the consumption-scape has been changed due to the influx of Chinese visitors. In the last few years, Chinese restaurants have mushroomed in historic sites to replace
French diners, leaving local blocks to appear as if they were another Chinese city (Callan, 2016).

In these processes, the booming speculative businesses tend to marginalize local citizens' position as consumers in the pursuit of maximum commercial profits. On the one hand, local consumers need to shop in rather remote and less popular areas, as major streets and prime locations are filled with tourist shoppers. On the other hand, they find themselves surrounded by similar shops with limited varieties of product that are detached from their everyday needs. Resistance thus surges among local residents and small shopkeepers due to the increasing segregation of the consumption-scape (Lee, 2014; Plummer, 2017).

\section{Disturbances of Social Order}

In the third type of conflict, while the locals' vital needs may not be threatened, conflict emerges when they witness the disruption of social orders caused by the tourist shoppers' unruly behaviors. Such disturbances can be vandalism, noise, chaos, or the infringement of local rules such as littering and cutting through the lines. In these cases, tourist shoppers are not as harmful to specific local individuals as they are to public spaces. However, the disturbance still permeates the lives of local citizens when social rules and everyday conventions are challenged.

In Tokyo, for instance, there has been an increase in complaints received by the Japanese police regarding the surge in buses carrying Chinese shoppers that causes parking chaos in major retailing districts such as Ginza (Demetriou, 2016). Some actions have been taken by the authority to "protect" Japanese residents and their local lifestyles. In Kyoto, a prominent historic tourist city in Japan, the tourism authority has published brochures to inform visitors of Japanese culture, and to clearly define and identify the "dos" and "don'ts" for foreign visitors (Kim, 2015).

The disturbances caused by shopping tourism engender a clash with local social orders that could turn into more intense conflicts. In Hong Kong, for instance, traffic jams and garbage piles as consequences of overwhelming mainland Chinese tourists fueled waves of protest among local residents near primary tourist spots, where Chinese tourist shoppers had been accused for voracious buying that distorts the local social order (Liu, 2014). 


\section{Conclusion: Future Research on Sustainable Consumption-Scape in Global Tourist Cities}

In this review article we discussed the neoliberal presuppositions that guided much of shopping tourism's uneven development, and identified three types of conflict pertaining to the tension between local residents and tourist shoppers. Whereas one may assume that the cultural and social costs could be tolerable if economic interests are significant, the three types of conflict discussed show that the national economic interests cannot directly translate into local citizens' well-being without considering their everyday struggles and encounters. In fact, a policy that helps increase the revenues and commercial profits of some may lead to issues such as soaring rents and impose pressure on the general population, who suffer first-hand from the undesirable costs of shopping tourism. Understanding these unwelcome characteristics of the emerging shopping tourism and their interactions with the local communities is therefore crucial for policy makers who aim to precisely evaluate the tourism impact and for scholars who are interested in the dynamic, coconstitutive consumption-scape torn by grassroots forces and the inbound tourist capital.

We suggest three avenues for future studies in international tourism. First, while local communities' attitudes toward tourism development are conceivably influenced by the residents' evaluations of potential interests and costs to the society as a whole, more attention needs to be paid to the unequal distribution of both interests and costs across different entities and communities within the same society. Significant economic interests brought by shopping tourism should not be presumed to benefit local communities. For example, if tourists splurge on global luxury brands when they travel overseas, the revenue may benefit specific retailing giants or monopolies that have limited connections with local businesses.

Second, future research may examine how international shopping tourism can be regulated and developed in ways that are sustainable for both local communities and foreign tourists. Although this article critically reflects on how local residents' interests have been undermined by overwhelming shopping tourists, it should be noted that the visitors could also be vulnerable and even be stereotyped as gullible consumers. For example, World Duty Free in the Heathrow Airport was accused of discriminating against Chinese customers by setting a higher bar for them to receive discounts than for other non-Chinese tourists (Allen, 2018). While traveling overseas, due to the lack of language, cultural, time, and social resources, tourists are often at a disadvantage even if they are aware of unfair treatment. It would be worthwhile to study how the protection for foreign visitors can be institutionalized and enforced to diminish external costs for settling shopping-related disputes.

Third, future studies may consider extending this article by discussing how tourist shoppers have inadvertently altered the demarcation between local and foreign practices in the marketplace. With the development of tourist-oriented businesses, local communities may strive to counterbalance such trend by acts such as supporting local businesses and claim local identities through specific brands, services, and goods, which may or may not involve confronting visitors in large-scale consumer movement.

In other words, the changing connotations about being local and being touristy could be manifested in various levels of practice, including petit shopping decisions in the residents' everyday context that can be deemed as "political" because they are set out for public good and moral ideologies (Thompson, 2011). In this regard, local consumers' reaction offers a new arena for scholars to investigate how the "locals versus visitors" boundary work can be politicized and contested in the marketplace under specific sociocultural conditions and their corresponding discourses. Therefore, studying how the locals develop coping strategies and perform political consumption to hopefully counterbalance the neoliberal trend and the "invisible hand" would cast new insights into tourism studies.

\section{References}

Allen, K. (2018, February 12). Heathrow duty free Chinese discrimination 'unacceptable.' $B B C N e w s$. Retrieved from http://www.bbc.com/news/blogs-trending-43030291

Anwar, S., \& Sohail, M. (2004). Festival tourism in the United Arab Emirates: First-time versus repeat visitor perceptions. Journal of Vacation Marketing, 10(2), 161-170.

Brasor, P., \& Tsubuku, M. (2015, August 23). Chinese shoppers keep Japan's tills ringing. The Japan Times. Retrieved 
from https://www.japantimes.co.jp/news/2015/08/23/ business/economy-business/chinese-shoppers-keepjapans-tills-ringing/\#.WddjkFuCyUk

Callan, A. (2016, July 31). Pardon your French: Chinese tourists and a clash of cultures in Paris. Al Jazeera. Retrieved from http://www.aljazeera.com/blogs/2016/07/ pardon-french-chinese-tourists-clash-cultures-paris160727093734703.html

Coldwell, W. (2017, August 10). First Venice and Barcelona: Now anti-tourism marches spread across Europe. The Guardian. Retrieved from https://www.theguardian. com/travel/2017/aug/10/anti-tourism-marches-spreadacross-europe-venice-barcelona

Demetriou, D. (2016, February 15). China's 'explosive shopping' sprees bring chaos to Tokyo roads. The Telegraph. Retrieved from http://www.telegraph.co.uk/news/world news/asia/japan/12157333/Chinas-explosive-shoppingsprees-bring-chaos-to-Tokyo-roads.html

GovHK (2015, June). Visiting Hong Kong. Retrieved from https://www.gov.hk/en/nonresidents/visitinghk/cityatt/ index.htm

Grieshaber, K. (2013, April 26). Baby food shortage in Europe due to China demand. The San Diego Union Tribune. Retrieved from http://www.sandiegouniontribune. com/sdut-baby-food-shortage-in-europe-due-to-chinademand-2013apr26-story.html

Hall, C. M. (2006). Urban entrepreneurship, corporate interests and sports megaevents: The thin policies of competitiveness within the hard outcomes of neoliberalism. The Sociological Review, 54(2), 59-70.

Harvey, D. (2005). A brief history of neoliberalism. Oxford, UK: Oxford University Press.

Holly T. (2002). Shopping spree. Travel Agent, 314, 1.

Hong, C. (2015, December 22). Shopping sprees of Chinese in Japan offer much food for thought. China Daily. Retrieved from http://www.chinadaily.com.cn/ opinion/2015-12/22/content 22769440.htm

Horwitz, J. (2017, September 13). A high-profile law firm has filed a complaint alleging Macy's racially profiles Asian shoppers. Quartz. Retrieved from https://qz.com/1076140/ the-firm-wigdor-law-has-filed-a-complaint-allegingmacys-m-racially-profiles-asian-shoppers/

Jacobs, A. (2008, December 2). Chinese release increased numbers in tainted milk scandal. The New York Times. Retrieved from http:/www.nytimes.com/2008/12/03/ world/asia/03milk.html?rref=collection\%2Ftimestopic $\% 2$ FMelamine

Josiam, B., Kinley, T., \& Kim, Y. (2005). Involvement and the tourist shopper: Using the involvement construct to segment the American tourist shopper at the mall. Journal of Vacation Marketing, 11(2), 135-154.

Kim, S. (2015, August 12). Kyoto's etiquette manual for tourists. The Telegraph. Retrieved from http://www. telegraph.co.uk/travel/destinations/asia/japan/kyoto/ articles/Kyotos-etiquette-manual-for-tourists/

Knopp, T. R. (1981). Tourism, the local interests, conflict or compromise! Tourism Recreation Research, 6(1), 23-28.
Korporaal, G. (2017, March 29). China's pro-shoppers leave locals empty handed in formula aisle. The Australian. Retrieved from http://www.theaustralian.com.au/busi ness/in-depth/global-food-forum/chinas-proshoppersleave-locals-empty-handed-in-formula-aisle/news-story/ d2c41ce82792381fe0d3ba5fbbd2ad56

Lee, D. (2014, December 25). 56 suspected mainland Chinese cross-border traders arrested in Hong Kong. South China Morning Post. Retrieved from http://www.scmp. com/news/hong-kong/article/1668614/56-suspected-mainland-chinese-cross-border-traders-arrestedhong-kong

Liu, J. (2014, July 1). Hong Kong tensions rise over 'parallel traders'. BBC News. Retrieved from http://www.bbc. com/news/business-28093730

Lloyd, R. (2002). Neo-bohemia: Art and neighborhood redevelopment in Chicago. Journal of Urban Affairs, 24(5), $517-532$.

Mangin, V. (2015, August 25). The world's most influential shoppers. BBC Capital. Retrieved from http:// www.bbc.com/capital/story/20150824-the-worlds-mostinfluential-shoppers

Mollman, S. (2015, December 1). Japan's buzzword of the year means 'an explosive shopping spree by the Chinese.' Quartz. Retrieved from https://qz.com/563304/japansbuzzword-of-the-year-means-an-explosive-shoppingspree-by-the-chinese/

Mosedale, J. (Ed.). (2016). Political economy of tourism: A critical perspective. London, UK: Routledge.

Park, K. S., Reisenger, Y., \& Noh, E. H. (2010). Luxury shopping in tourism. International Journal of Tourism Research, 12, 164-178.

Pei, X., Tandon, A., Alldrick, A., Giorgi, L., Huang, W., \& Yang, R. (2011). The China melamine milk scandal and its implications for food safety regulation. Food Policy, $36,412-420$

Plummer, R. (2017, August 17). Are tourists still welcome after protests? BBC News. Retrieved from http://www. bbc.com/news/business-40960443

Rainer, G. (2011). Constructing globalized spaces of tourism and leisure: Political ecologies of the Salta Wine Route (NW-Argentina). Journal of Rural Studies, 43, 104-117.

Ryall, J. (2015, December 2). Bakugai! Japan's new term for 'explosive' Chinese shoppers. South China Morning Post. Retrieved from http://www.scmp.com/news/asia/ east-asia/article/1886280/bakugai-japans-new-termexplosive-chinese-shoppers

Sonnenburg, S., \& Wee, D. (2016). Introduction to touring consumption. Journal of Consumer Culture, 16(2), 323-333.

Thompson, C. (2011). Understanding consumption as political and moral practice: Introduction to the special issue. Journal of Consumer Culture, 11(2), 139-144.

Wassener, B., \& Hui, M. (2013, July 4). Soaring rents in Hong Kong push out mom and pop stores. The New York Times. Retrieved from https://cn.nytimes.com/china/ 20130704/c04hongkong/en-us/ 